\title{
A GRAMÁTICA DA EXPERIÊNCIA DE ADOLESCENTES SOBRE O LUGAR ONDE VIVEM
}

\author{
(The grammar of experience of teenagers about the place where they live)
}

\author{
Miguel Ângelo Moreira ${ }^{1}$ \\ (Universidade e Brasília- UnB)
}

\begin{abstract}
The purpose is to analyze the lexical choices made by teenagers to represent the place where they live. The theoretical approach is stemmed from the perspective of Systemic Functional Linguistics (SFL), based on Halliday and Matthiessen (2014), and the Appraisal System developed by Martin and White (2005). The empirical and qualitative datawere obtained in a public school located in the Federal District. The research is part of the studies developed in the Brazilian Group of Discourse Studies, Poverty and Identities (DP-CNPq).Preliminary results show that adolescents represent the streets as a place of fear, insecurity and fragility in social life.
\end{abstract}

Keywords: Representation. Metafunction. Appraisal. Poverty. Teenagers

\section{RESUMO}

O propósito aqui é analisar quais as escolhas léxico-gramaticais realizadas por adolescentes para representarem o lugar onde vivem. O enfoque teórico insere-se na perspectiva da Linguística Sistêmico-Funcional (LSF), com base em Halliday e Matthiessen (2014), e do Sistema de Avaliatividade (SAv), desenvolvido por Martin e White (2005). Os dados empíricos de natureza qualitativa foram obtidos junto a uma escola pública do Distrito Federal. A investigação faz parte dos estudos desenvolvidos no Grupo Brasileiro de Estudos de Discurso, Pobreza e Identidades (DP$C N P q$ ). Os resultados preliminares apontam que os adolescentes representam as ruas como lugar de medo, insegurança e fragilidade para o convívio social.

Palavras-chave: Representação. Metafunção. Avaliação. Condição de risco. Adolescência

\section{Introdução}

O tema "violência" insere-se, neste estudo, por se tratar de uma categoria discursiva recorrente nos dados analisados neste artigo. A violência é um fenômeno pertencente a qualquer sociedade, mas se é um fenômeno, inerente aos seres vivos, não se sabe ao certo. Entretanto, pode-se sugerir que a violência cresce na medida em que os seres humanos buscam seu espaço social e sua sobrevivência natural (NOVO, 2006). Vários também são os tipos de violência: contra crianças; contra idosos e, sobretudo, entre os jovens (autores e vítimas. De acordo com a pesquisadora Helerina Novo (2006, p.10), "estamos vivendo a era da violência, uma era que coisifica e exclui os sujeitos sociais". De modo específico, a

\footnotetext{
${ }^{1}$ Mestre em Linguística pela Universidade de Brasília, onde realiza a etapa final de seu doutoramento, com a tese "Práticas discursivas e sociais na relação família-escola-comunidade: da realidade da adolescência ao discurso legal", a ser defendida em junho de 2015. É membro do Grupo Brasileiro de Estudos do Discurso, Pobreza e Identidades (REDLAD) e professor da Secretaria de Educação do Distrito Federal (SEDF, Brasil). Doutorado "Práticas discursivas e sociais na relação família-escola-comunidade: da realidade da adolescência ao discurso legal".
} 
violência é enfocada, no âmbito do trabalho ora apresentado, como um fenômeno que resulta da experiência de um mundo social, físico e mental, uma vez que o escopo central do estudo é descrever e interpretar um fenômeno invasivo, capaz de transformar vidas, bem como o imaginário, sobretudo, de adolescentes em situação de vulnerabilidade.

O objetivo deste artigo é, pois, analisar e discutir escolhas léxico-gramaticais, presentes no discurso de adolescentes e utilizadas para caracterizar o espaço onde vivem. Busca-se, em um tempo real de curta duração, o registro do olhar minucioso de adolescentes nas ruas de Santa Maria, espaço urbano que hoje constitui uma das denominadas regiões administrativas do Distrito Federal. ${ }^{2}$ Para tanto, analisamos 32 (trinta e dois) relatos escritos produzidos por jovens estudantes de uma escola da rede pública de ensino do Distrito Federal, situada no espaço de Santa Maria. Cabe ressaltar que, por se tratar de uma pesquisa acadêmico-científica realizada com pessoas em situação de menoridade, tem-se a aprovação do Comitê de Ética da Universidade de Brasília, o que contribui para apoiar os procedimentos éticos assumidos. O trabalho ora apresentado integra constitui parte de uma pesquisa maior, desenvolvida junto ao Grupo Brasileiro de Estudos de Discurso, Pobreza e Identidades, (DPCNPq).

O enfoque teórico insere-se na perspectiva da LSF de Halliday (1985, 1994, 2004, 2014) e do Sistema de Avaliatividade, desenvolvido por Martin e White (2005). O enlace teórico-metodológico entre essas vertentes configura os instrumentos de análise (con)textual. Os resultados preliminares apontam para sentidos construídos pelos adolescentes que representam o lugar onde vivem. As escolhas lexicais dos jovens, registradas em seus textos escolares, para definir suas respectivas experiências nas ruas, configuram a maneira como eles avaliam a própria realidade.

$\mathrm{O}$ artigo envolve quatro partes, a contar com esta introdução. Na segunda parte, apresentamos os vértices teóricos que sustentam a estrutura analítica. Em seguida, na seção 3, abordamos uma breve contextualização sobre a geração dos dados, antes de explicitar a análise de relatos produzidos por adolescentes em oficinas de letramento, o que se encontra na seção 4. As considerações finais significam uma contribuição para direcionar o seguinte questionamento: se as ruas são definidas como lugar de medo, insegurança e fragilidade para o convívio social e esses adolescentes estão inseridos nesse lugar, significa que a realidade da adolescência, sob a ótica dos próprios adolescentes, constitui uma condição de risco.

\footnotetext{
${ }^{2}$ Santa Maria é uma região administrativa do Distrito Federal brasileiro. Mais informações sobre essa região, podem ser consultadas no site http://www.santamaria.df.gov.br (Acessado em 03/09/2014). 192
} 


\section{Instrumentos teóricos}

Nesta seção, apresentaremos os instrumentos de análise (con)textual. Para tanto, buscamos delimitar uma das ferramentas analíticas propostas por Halliday. Trata-se da metafunção ideacional, que realiza o Sistema de Transitividade, o que foi abordado na subseção 2.1. Em seguida, na subseção 2.2, abordamos a categoria Apreciação, que integra o Sistema de Avaliatividade - categoria selecionada para complementar a análise.

As duas teorias constituem um amálgama complexo que possibilita a realização de pesquisas sobre questões linguísticas, sociais e políticas num universo de conhecimento de práticas institucionais. Não seria, portanto, concebível a apresentação completa dessas teorias na elaboração deste artigo. Optamos, pois, pela delimitação das categorias que "nasceram" dos dados, pois são os dados que indicam as categorias analíticas relevantes para analisar o discurso de adolescentes sobre a representação que fazem do lugar onde vivem.

\subsection{Sob a lupa do Sistema de Transitividade}

É preciso comentar que a categoria escolhida para embasar a análise da seção 4 é a representação, constitutiva do significado representacional da linguagem, proposto por Fairclough (2003). O conceito de representação, adotado neste trabalho, diz respeito aos modos de representar aspectos ligados aos mundos - "material", "mental" e "social", contidos em textos, o que corresponde à função ideacional de Halliday. Para Fairclough (2003, p. 134), em um período simples de texto, podem-se abordar a experiência do mundo físico, mental (dos pensamentos, sentimentos, sensações e desejos), além dos aspectos do mundo social.

Trata-se da expressão da experiência do falante em relação ao mundo real (incluindo as noções de tempo e espaço) e ao mundo interior de sua própria consciência, ambas ancoradas na representação dos significados discursivos que expressam a experiência linguística do falante, organizada pelo Sistema de Transitividade da língua. Além da metafunção ideacional, Halliday propôs mais duas funções, sendo que todas se organizam simultaneamente na produção do discurso: a função Interpessoal, que realiza o Sistema de Modo, e a função Textual, responsável pela organização do Sistema Temático e de Informação. Essas duas últimas funções não serão tratadas neste artigo. Busca-se apenas delimitar o Sistema de Transitividade, responsável por expressar a experiência humana como um processo, no qual intervêm um ou mais participantes, além das circunstâncias associadas. Para Halliday e Matthiessen (2014, p. 213), “cada processo provê seu próprio modelo ou 
esquema, que constrói um domínio particular de experiência como uma figura de um tipo particular", ou seja, cada processo dá corpo a esquemas conceituais, traduzidos pela gramática da experiência como significados discursivos (MOREIRA, 2007, p. 40).

$\mathrm{Na}$ função Ideacional, trabalhamos a oração como representação da visão de mundo materializada textualmente no discurso. Essa representação constitui o que Halliday chama de Gramática da Experiência. De acordo com esse autor, o discurso (aspecto representacional) é visto como um modo de representar facetas do mundo, tais como - ações e eventos do mundo material (ou mundo do "fazer"); sentimentos, desejos, crenças, valores etc. do "mundo mental" (ou mundo da consciência); e as relações abstratas do mundo social. Para Ghio e Fernandez (2005, p. 82), "estes tipos constituem os processos básicos ou principais do sistema de transitividade de uma língua", que se associam a atores sociais e circunstâncias para formar a célula básica da oração, conforme ilustra o Esquema 1 abaixo:

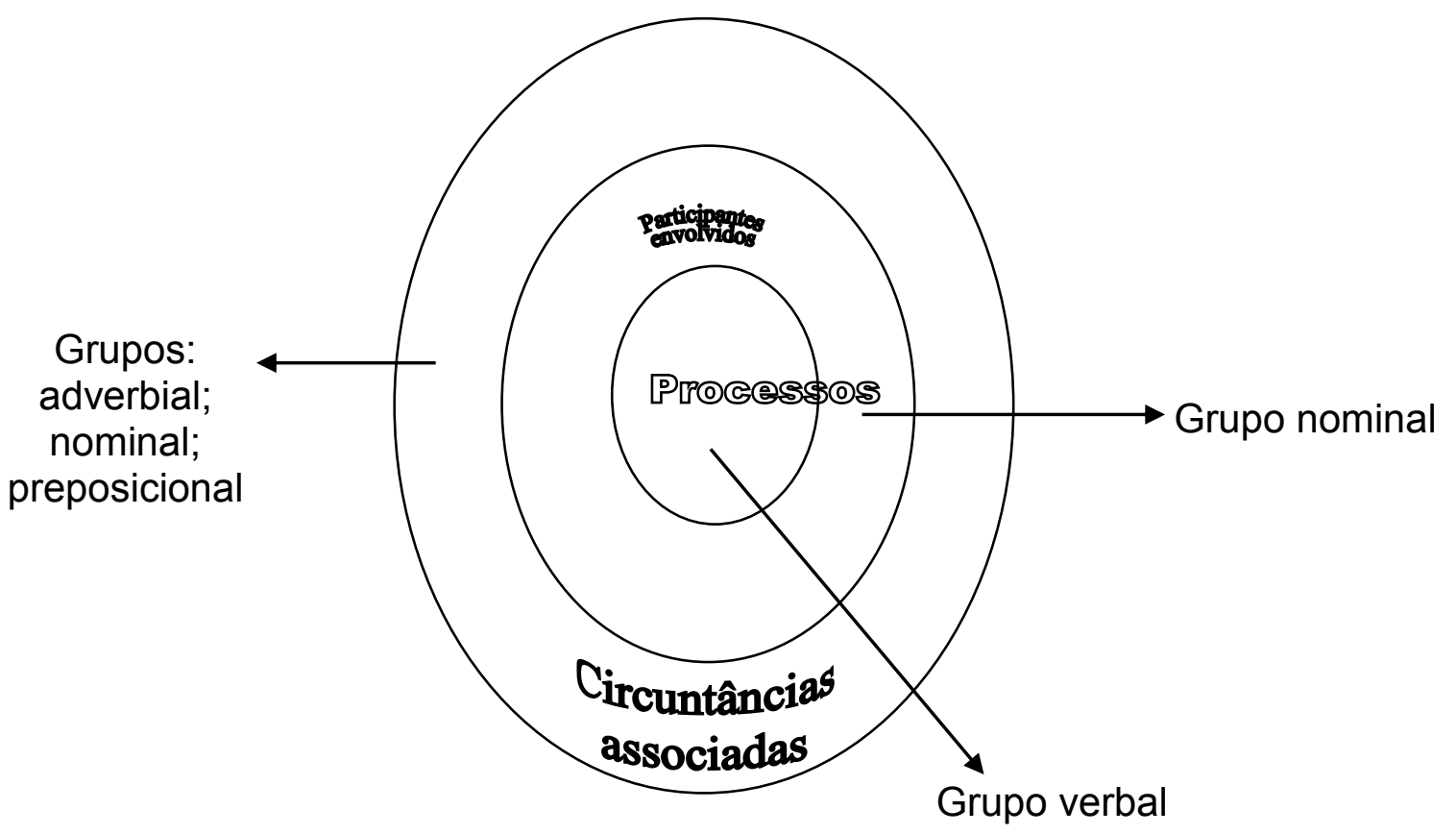

Esquema 1: Célula da Transitividade Fonte: Moreira (2007, p. 39).

O Esquema 1 sugere uma representação metafórica do chamado Sistema de Transitividade como se fosse uma célula, na qual "cada processo é associado com diferentes papéis dos participantes, ocorrendo em diferentes configurações” (EGGINS, 2004, p. 214). De acordo com esse Esquema, o Grupo Nominal e o Grupo Verbal constituem as categorias 
gramaticais típicas de realização das circunstâncias, processos e participantes, de acordo com o direcionamento das setas. Como se pode notar, a diagramação mostra o processo como elemento nuclear da Célula da Transitividade, que faz "nascer" a Gramática da Experiência. Para Halliday e Matthiessen (2014, p. 221), "essa interpretação tripartite é o que subjaz a distinção gramatical das classes de palavras em verbos, substantivos e o resto" - um padrão que de uma forma ou de outra é provavelmente universal entre as línguas humanas. Trata-se, então, de aspectos presentes nos Universais Linguísticos, propostos pela LSF.

Ainda segundo Halliday e Matthiessen (2014, p. 213), essa gramática “constrói o mundo da experiência dentro de uma série de tipos de processos". O tipo de processo representado numa oração deve levar em conta a função do participante no contexto discursivo e as consequências dos seus atos, assim a representação da visão de mundo do falante/escritor dependerá de sua escolha lexical.

\subsection{Apreciação no Sistema de Avaliatividade}

A maneira como o indivíduo se posiciona na interação a partir de suas escolhas lexicais, modalizadas ou não, pode expressar o grau de comprometimento em relação à verdade do que diz, assim como indicar se essa verdade é boa ou ruim em termos de avaliação. De acordo com a perspectiva sistêmico-funcional, a linguagem possibilita um número muito grande de recursos pelos quais se podem expressar emoções, crenças, desejos, avaliações etc a partir de seus contextos de uso. De acordo com Halliday (2002, p. 8), “esses recursos têm transformado (ou, pelo menos, estão em processo de transformação) a maneira como a linguagem olha a partir do interior". É nessa perspectiva que muitos estudiosos da LSF buscam descrever como a avaliação está marcada no discurso. ${ }^{3}$

Conforme prescreve Martin e White (2005, p.31), o Sistema de Avaliatividade é compreendido como um recurso para construir as Relações; ou seja, o contexto de situação instanciado na relação realizada pela Metafunção Interpessoal. Nessa perspectiva, a Avaliatividade está localizada no sistema semântico do discurso e realizada principalmente no Sistema de MODO, conforme podemos visualizar no Esquema 2 abaixo:

\footnotetext{
3 Entre eles: Eggins e Slade (1997), Hunston (2000) e Hunston e Thompson (2000), além dos trabalhos de Martin (2000, 2002, 2003, 2004) e colaboradores, tais como Martin e Rose (2007); Martin e White (2005). No Brasil, destacam-se os estudos de Vian Jr. (2009, 2010) e Almeida (2010).
} 


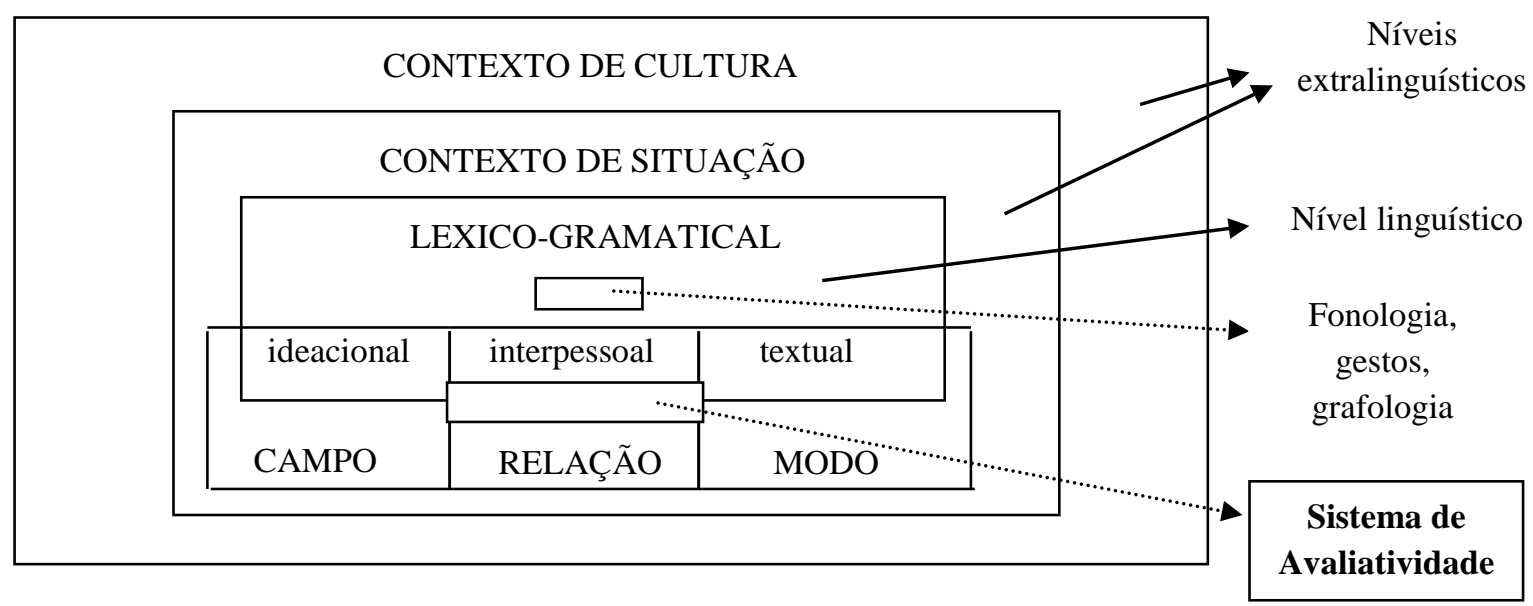

Esquema 2: O Sistema de Avaliatividade dentro dos estratos da linguagem

O Sistema de Avaliatividade, a partir da perspectiva apresentada no Esquema 2, é realizado dentro do sistema da semântica do discurso (níveis extralinguísticos) e ativado no sistema lexicogramatical (nível linguístico) a depender da forma expressa pelo nível grafofonológico. "Trata-se de um sistema na interface entre semântica do discurso e léxicogramática, da realização dos significados no texto através dos recursos disponíveis na semântica do discurso" (VIAN JR., 2009, p. 114). Essa interface é marcada textualmente na avaliação, pois segundo Vian Jr. (2009, p. 113), "ao selecionar o léxico avaliativo quando julgamos algo, partimos de sistemas semânticos, que são realizados léxico-gramaticalmente de forma a reforçarmos, ampliarmos ou reduzirmos, aquilo que avaliamos". Para tanto, esse sistema opera a partir de três recursos semântico-discursivos: Atitude, Engajamento e Gradação, os quais descrevemos no Quadro 1 a seguir:

QUADRO 1: Sistema de Avaliatividade

\begin{tabular}{|c|c|c|l|}
\hline \multirow{4}{*}{$\begin{array}{c}\text { Sistema de } \\
\text { Avaliatividade }\end{array}$} & Atitude & Afeto & $\begin{array}{l}\text { Consiste nas emoções linguisticamente realizadas no } \\
\text { discurso }\end{array}$ \\
\cline { 3 - 4 } & & $\begin{array}{l}\text { Constrói linguisticamente as avaliações } \\
\text { comportamento das pessoas }\end{array}$ & de \\
\cline { 2 - 4 } & Apreciação & $\begin{array}{l}\text { Refere-se à maneira pela qual os falantes avaliam o texto } \\
\text { (oral ou escrito) ou o processo }\end{array}$ \\
\cline { 2 - 4 } & Gradação & \multicolumn{3}{|l}{} \\
\cline { 2 - 4 } & Engajamento & \\
\hline
\end{tabular}

Fonte: adaptado de Martin e White (2005, p. 38). 
As avaliações podem, por exemplo, ser mais ou menos intensas, pouco ou muito enfáticas, mais ou menos distantes do nosso interlocutor e assim por diante, o que vai depender do contexto de situação em que a linguagem está sendo empregada. De maneira geral, as avaliações expressam a atitude dos falantes/escritores. Trata-se um recurso semântico-discursivo que serve para realizar os significados interpessoais relacionados aos sentimentos e emoções, julgamentos de caráter e apreciações das coisas e dos objetos. Tais sentimentos podem ser traduzidos através de participantes ou de alguns tipos de processos, o que justifica o interesse desta pesquisa pelo Sistema de Avaliatividade como recurso complementar às análises propostas na seção 4.

A Atitude, como elemento central no processo avaliativo, exerce a função de expressar, por meio do discurso, os posicionamentos avaliativos dos atores sociais envolvidos numa situação de interação. Nesse subsistema, estuda-se a maneira como os atores sociais negociam emoções, fazem julgamentos e avaliam o contexto de situação no qual estão inseridos. Dessa forma, para expressar a Atitude, os usuários da língua utilizam três recursos semânticos: Afeto, Julgamento e Apreciação. O Afeto permite identificar quais emoções estão sendo expressas linguisticamente no discurso, sendo que essas emoções podem ser positivas ou negativas em relação ao seu contexto de uso. Já o Julgamento dá pistas sobre o comportamento das pessoas, ou seja, qual o posicionamento ético do indivíduo em determinado contexto de situação. Por fim, a Apreciação ocorre quando expressamos nossa avaliação (ou opinião) sobre um objeto qualquer. Aqui nos restringimos a uma breve apresentação da categoria Apreciação, que foi utilizada como instrumento de análise textual neste artigo.

A Apreciação, segundo Martin e White (2005, p. 43), “envolve avaliações de fenômenos semióticos e naturais, de acordo com as formas pelas quais eles são valorizados ou não em um determinado campo"; ou seja, refere-se à maneira pela qual os falantes avaliam a estética das coisas, seguindo padrões institucionalizados. O valor dado a coisas (e/ou a pessoas) está ligado à forma com que tal coisa (ou pessoa) pode ou não ser aceita socialmente. Conforme a análise constante na seção 4, ao avaliar o "lugar onde vive", os adolescentes utilizam categorias de Apreciação, tais como "perigoso", para caracterizar a percepção de mundo sobre a cidade onde moram e as ruas onde frequentam. É o que podemos observar no fragmento oracional: Eu vejo as ruas um lugar perigoso, extraído do excerto 03 (ver seção 4). Nota-se, nesse fragmento, que a marca lexical, materializada no epíteto "perigoso", corresponde ao sentimento de reação diante do contexto de situação de violência a qual vivencia. A reação é uma das categorias da Apreciação. 
De acordo com Martin e White (2005, p. 56), a reação se refere a como reagimos às coisas. Para mostrar sua reação diante do contexto de situação de perigo, o adolescente recorre a uma série de processos materiais, os quais são projetados pelo "olhar" atento do jovem sobre o ambiente das ruas - é o que mostra o fragmento seguinte: Nessas ruas, eu já vi de tudo, gente sendo assaltada, gente sendo assassinada, já vi malandros sendo "enquadrados", fumando maconha, cheirando pó (...). (também extraído do excerto 3). Com isso, as avaliações dos adolescentes acerca do lugar onde vivem implicam Apreciações com valores, quase sempre, negativos, o que demonstra, mais uma vez, a importância do Sistema de Avaliatividade como instrumento de análise (con)textual para desvendarmos a realidade de adolescentes em condição de risco sob a perspectiva da própria adolescência.

\section{Sobre a geração dos dados}

Os relatos analisados neste artigo fazem parte da aplicação do projeto Gêneros textuais, identidade, interpretação e produção textual: interpretando e construindo valores a partir de oficinas de letramento (MOREIRA, 2012). O projeto, que previa a realização de oficinas de letramento, foi desenvolvido numa escola pertencente à rede pública do Distrito Federal com estudantes do Ensino Médio, período vespertino, entre os anos de 2012 e 2013.

As oficinas de letramento previam a realização de várias atividades, tais como: leitura, debate, produção de textos, revisão textual, entre outras. Não cabe a este trabalho discutir cada atividade ou como o desenvolvimento delas contribuiu para o letramento dos adolescentes, embora as práticas de letramento perpassem pelo discurso desses jovens. Não obstante, o interesse desta investigação limitou-se a apenas uma das atividades, que resultou na produção de textos em forma de relatos autobiográficos, uma vez que os estudantes recontam parte de suas histórias de vida. No quadro abaixo, delineamos o contexto de situação e a conjuntura de geração dos relatos especificamente sobre a temática $O$ lugar onde vivo, conforme mostra o Quadro 2 abaixo: 
QUADRO 2: Seleção de relatos sobre a temática $O$ lugar onde vivo

\begin{tabular}{|c|c|c|c|c|}
\hline $\begin{array}{c}\text { Ações } \\
\text { (ano de } \\
\text { execução) }\end{array}$ & Texto-base & Tópico guia & $\begin{array}{c}\text { Quant. de } \\
\text { narrativas } \\
\text { selecionadas }\end{array}$ & $\begin{array}{c}\text { Quant. de narrativas } \\
\text { produzidas }^{4}\end{array}$ \\
\hline $\begin{array}{c}\text { Atividade } 1 \\
(2012)\end{array}$ & $\begin{array}{c}\text { ECA - Cap. II (Do } \\
\text { direito à liberdade, } \\
\text { respeito e } \\
\text { dignidade) }\end{array}$ & $\begin{array}{c}\text { "O lugar onde } \\
\text { eu vivo" }\end{array}$ & 03 & 10 \\
\hline $\begin{array}{c}\text { Atividade } 2 \\
\text { (2013) }\end{array}$ & $\begin{array}{c}\text { ECA (com ênfase } \\
\left.\text { no art. 5 }{ }^{\circ}\right)\end{array}$ & $\begin{array}{c}\text { Juventude, } \\
\text { drogas e } \\
\text { violência }\end{array}$ & 04 & 31 \\
\hline \multicolumn{2}{|l}{ Total de relatos selecionados } & 07 & 41 \\
\hline
\end{tabular}

O quantitativo de textos, mencionado no Quadro 2, dizia respeito a duas atividades que envolviam a temática "O lugar onde vivo". Para este artigo, selecionei apenas 07 relatos, os quais foram produzidos em dois momentos ${ }^{5}$. No primeiro momento, tem-se a Atividade 1, realizada em 2012. Nessa atividade, foram selecionados 03 relatos para análise. No segundo momento, tem-se a Atividade 2, ocorrida em 2013. Aqui, foram selecionados 04 relatos para a análise. As atividades, desenvolvidas nas oficinas, constituem sequências didáticas e temáticas específicas, as quais conformam os modos de produção dos textos.

É imprescindível mencionar que, para cada atividade, o professor utilizava como texto-base o Estatuto da Criança e do Adolescente, conforme tema abordado e trabalhado em sala de aula. Por exemplo, para trabalhar o tema "O lugar onde vivo", o texto-base foi o Capítulo II do ECA, conforme expõe o Quadro 2. Na realização das atividades, os alunos receberam orientações sobre as características do gênero textual debate (estrutura, função social, conteúdo, tipo de linguagem), fizeram leituras, reflexões e debates acerca dos direitos ligados à liberdade, ao respeito e à dignidade de crianças e adolescentes e, por fim, foram incentivados a produzirem relatos de vida sobre a temática desenvolvida em sala de aula.

Frisa-se, também, que este artigo não busca descrever cada atividade, pois o interesse foi apenas o de analisar o produto das atividades de letramento: os relatos escritos produzidos pelos estudantes. Para o bom andamento das atividades, foi adotada uma postura ética, ouvindo as experiências e respeitando as opiniões de cada ator social envolvido nas práticas de letramento. Nesse sentido, o letramento como evento social serviu, não apenas para a produção e ampliação de conhecimentos referentes a gêneros discursivos situados (leis e estatutos), mas também como ponte para a produção de textos em forma de depoimentos.

\footnotetext{
${ }^{4}$ Essa quantidade diz respeito aos dados gerados na pesquisa de Doutorado (em andamento).

5 Conforme destacamos no Quadro 2, a quantidade de relatos produzidos nas oficinas de letramento é bem superior ao número selecionado para análise neste artigo. Entretanto, entendemos que, para a análise, o quantitativo de 07 relatos é suficiente para atender nosso objetivo.
} 
Vale acrescentar, também, que a geração de dados no período de pesquisa de doutorado também se orientou por procedimentos éticos, não apenas por se tratar de uma obrigatoriedade institucional, mas por se constituir em uma pesquisa-ação com vistas ao desenvolvimento de propostas transformadoras, inscritas no âmbito dos estudos críticos do discurso (CHOULIARAKY E FAIRCLOUGH, 1999). Trata-se, pois, de meu compromisso moral e político, em termos de valores éticos, pelo trabalho dedicado a jovens que vivem em condição de risco social/exclusão educacional.

Com base nesses relatos, produzidos em sala de aula, é que pudemos fazer uma breve análise sobre a experiência de mundo de um grupo de alunos, de modo a aproximar respostas à questão de pesquisa: quais as representações discursivas dos adolescentes sobre o lugar onde vivem? Para tanto, buscamos compreender como esses jovens se posicionam em seus discursos e quais as escolhas lexicais foram realizadas.

Desse modo, interessou-nos aplicar o Sistema de Transitividade, com base na LSF, e a categoria Apreciação do Sistema de Avaliatividade, como ferramentas analíticas principais voltadas para a compreensão da experiência de mundo dos atores sociais, envolvidos nesta pesquisa. Tanto a aplicação teórica quanto a análise foram conduzidas pelos dados; pois são os dados que indicaram as categorias analíticas e não o contrário. $\mathrm{O}$ meu foco principal foi sobre categorias discursivas e não apenas sobre categorias linguísticas. Isso porque a representação dos atores sociais está ligada às escolhas léxico-gramaticais instanciadas em eventos sociais, os quais materializam suas experiências de mundo. Portanto, a escolha de uma categoria analítica em detrimento de outra é questão de estratégia de pesquisa. Nessa lógica, a análise foi conduzida pela temática abordada nos relatos (categoria discursiva), que, por sua vez, comandou o tipo de categoria analítica a ser usada em cada caso.

\section{Representações linguístico-discursivas de adolescentes sobre o lugar onde vivem}

$\mathrm{O}$ artigo envolve a análise de constituintes léxico-gramaticais presentes em relatos de vida, registrados em textos produzidos em sala de aula por adolescentes da faixa etária de 14 a 17 anos. Trata-se de um recorte de dados relativos à pesquisa de Doutorado concluída recentemente (MOREIRA, 2015).

Considerando que a representação social dos alunos está associada à matrícula de adolescentes em um contexto sociopolítico (a escola), apresento excertos, transcritos em textos cuja temática é "Fale do lugar onde você vive". Nesses textos, os adolescentes projetam discursos, dos quais emanam crenças, valores, visões de mundo, sentimentos e experiências 
sobre si e sobre "outros". As representações discursivas de adolescentes dizem algo sobre esses atores sociais, traçam seus modos de ser, definem suas identidades, caracterizam suas práticas sociais. O que chamou a atenção, nas observações participantes e na análise dos dados, foi a representação do "lugar onde vivem" quase sempre descrito como um ambiente atribuído como "perigoso". Esse atributo encontra-se marcado textualmente no discurso dos adolescentes, conforme destacam os excertos (1) e (2), os quais relaciono a seguir:

1. O lugar onde eu vivo é muito perigoso, esse lugar que nois ta vivendo tem que para com a violência. Mais nois ta lutando pra um lugar melhor. Nois que um lugar pra nois viver em paz. (Stephan -16 anos - Atividade 1$)^{6}$

2. O lugar onde eu vivo é um lugar perigoso. Ultimamente tem muitas pessoas usando drogas essas drogas do mundo de hoje estão acabando com as pessoas; alguém tem que acabar com essa violência toda. (Pedrợ, 16 anos - Atividade 1)

Inicialmente, é possível observar que os adolescentes começam os relatos com orações relacionais. Observa-se, nesses excertos, a repetição do adjetivo perigoso. No que concerne ao Sistema de Transitividade, os participantes de orações relacionais estabelecem uma relação que pode ser de identificação ou atribuição. No caso dos excertos (01) e (02), a relação entre os participantes é de Atribuição O Esquema 3 permite mostrar as categorias que compõem essa relação.Vejamos.

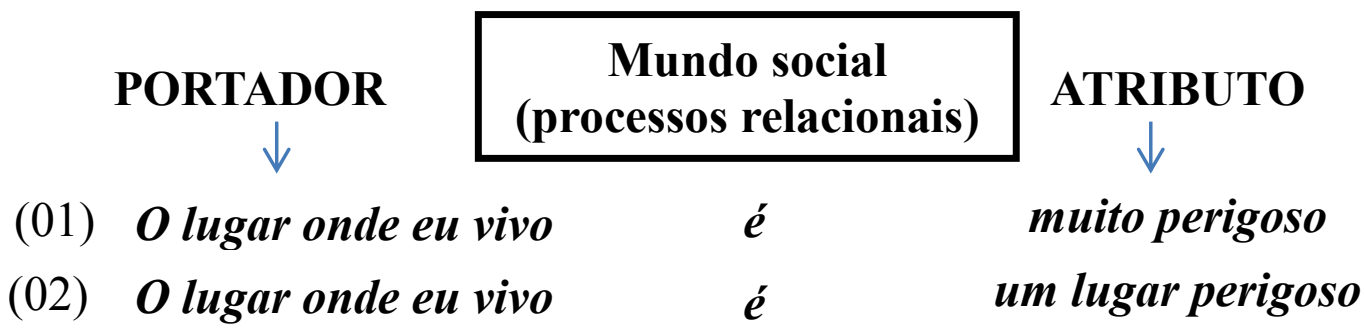

Esquema 3: Processo relacional atributivo

No Esquema 3, destaca-se algumas categorias que fazem parte da Gramática da Experiência, proposta por Halliday. A categoria em destaque é o processo relacional. Esse processo aborda de maneira peculiar o uso do verbo "ser", na medida em que codifica significados sobre "estados de ser" (Eggins, 2004, p. 237). Cunha e Souza (2007, p. 58)

\footnotetext{
${ }^{6}$ Por questões éticas, os adolescentes serão denominados por pseudônimos, de modo a preservar a identidade de cada participante desta pesquisa.
} 
definem esses processos da seguinte forma: "são aqueles que estabelecem uma conexão entre entidades, identificando-as ou classificando-as, na medida em que associam um fragmento da experiência a outro". No caso das unidades de informação (1) e (2), observa-se uma relação de classificação entre os participantes "O lugar onde eu vivo", que corresponde ao Portador, e o adjetivo "perigoso".

Cabe mencionar, do ponto de vista do Sistema Temático (outro sistema proposto por Halliday), que o Portador é o tema dado, uma vez que remete aos adolescentes o título sugerido por mim para o desenvolvimento dos relatos, a saber: "o lugar onde vivo". Já o restante da oração constitui a informação nova; ou seja, aquilo que os adolescentes escolheram para falar desse lugar. A escolha mais recorrente foi pelo adjetivo "perigoso". Esse adjetivo configura o Atributo (que é o segundo participante do processo relacional atributivo). O Atributo, no caso, representa, para esses jovens, o lugar onde vivem. Quer dizer, essa é a maneira como esses adolescentes avaliam esse lugar. A relação entre esses dois participantes é caracterizada pelo processo relacional "ser", que codifica significados sobre os "modos de ser" das ruas em que os adolescentes perambulam. Nessa perspectiva, o processo relacional permite identificar os estilos tematizados no discurso desse adolescente. No que concerne ao significado identificacional da linguagem, "estilos", na perspectiva de Fairclough (2003, p. 159), apontam maneiras de ser. Nesse sentido, a estrutura oracional O lugar onde eu vivo é muito perigoso trata, a meu ver, de uma auto-avaliação que está ligada ao aspecto discursivo das formas de "ser".

A propósito, a avaliação pode ser marcada textualmente por meio de Atributos em orações relacionais (HOOD, 2004, p. 76). Quer dizer, essa é a maneira como eles avaliam esse lugar. Ou seja, ao identificar as ruas como "um lugar perigoso" ou que contém "perigos" (violência; mundo do crime; drogas), as posições dos atores sociais no discurso constituem os estilos marcados semioticamente, os quais refletem a formação das identidades desses jovens num ambiente de risco. Ressalta-se que esse posicionamento (ideológico) é marcado textualmente na avaliação dos adolescentes sobre o contexto de situação em que se mostram inseridos. Em outras palavras, ao avaliar "o lugar onde mora ou vive" como um "lugar perigoso", os atores sociais apreciam negativamente esse ambiente. Para tanto, a avaliação é realizada pelo atributo "perigoso", que pode ser explicado, segundo o Sistema de Avaliatividade, como uma forma de Apreciação do tipo Reação-Qualidade. Essa categoria diz respeito à avaliação sobre a qualidade de algo - no que concerne aos excertos destacados aqui, a qualidade "perigoso", atribuída ao lugar onde os adolescentes moram, configura um contexto de situação negativo. Por isso, os jovens reagem negativamente diante desse 202 
contexto a partir da projeção de comportamentos que envolvem atitudes, tais como: "entrar no mundo do crime" (excerto 1) ou "usar drogas" (excerto 2). Tais reações estão associadas ao cenário em que esses jovens estão inseridos. Trata-se da maneira como eles se identificam nesse contexto ou como esses jovens representam o contexto das ruas - é o que também se observa nos excertos (3) e (4) a seguir:

3. Eu vejo as ruas um lugar perigoso, mas também há lugares tranquilos como em parques, áreas verdes. Nessas ruas, eu já vi de tudo, gente sendo assaltada, gente sendo assassinada, já vi malandros sendo "enquadrados", fumando maconha, cheirando pó. (...) Já vi pessoas pichando muros. Na minha rua, dois irmãos foram assassinados por dívidas de drogas. (Yves -17 anos - Atividade 1)

4. Eu já vi sim pessoas usando drogas, lá onde eu moro por exemplo (...) já teve tiroteio o primeiro foi

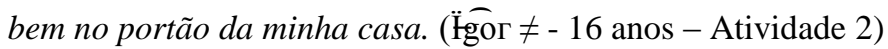

Ao analisar a transitividade dos verbos, contidos nos excertos (3) e (4), destaca-se a recorrência ao verbo "ver" (em negrito). Trata-se de um processo mental perceptivo, segundo a Gramática da Experiência, proposta por Halliday e Matthiessen (2014, p. 257). Esse processo faz parte do mundo da consciência desses jovens. Nesse caso, eles se posicionam como participantes Experienciadores, que experimentam o "ver".

De acordo com Cunha e Souza (2007, p. 58), os “processos mentais lidam com a apreciação humano do mundo. Através de sua análise é possível detectar que crenças, valores e desejos estão representados em um dado texto". Nesse tipo de processo, têm-se dois participantes: o Experienciador e o Fenômeno, caracterizados, respectivamente, como o participante que experimenta o "ver" (ou o "sentir") e o segundo é o fato que é "visto" (ou "sentido", "percebido", “desejado") pelo Experienciador. No caso dos excertos em análise, os participantes experienciadores são os próprios adolescentes e os fenômenos configuram o contexto das ruas, particularmente da cidade-satélite de Santa Maria, onde esses jovens moram e convivem.

Nessa perspectiva, os excertos (3) e (4) permitem sugerir que "os olhos" (ou a percepção visual) desses jovens funcionam como uma espécie de projetor que projeta o contexto de situação das ruas dessa cidade. Contexto que é representado como perigoso, a exemplo dos excertos (1) e (2). Cabe destacar que esse quatro excertos definem a experiência interiorizada pelos adolescentes. Ambas as experiências, voltadas para o mundo do "ser" e do "ver", projetam os comportamentos observados pela lente do contexto de situação descrito. Tais comportamentos (sublinhados nos excertos 3 e 4) estão inseridos no lugar onde esses 
jovens vivem. Essa é maneira como os colaboradores desta pesquisa avaliam os comportamentos e o cenário descrito. Nesse momento, parece haver uma espécie de entropia, ou seja, os adolescentes internalizam esses comportamentos ("usar drogas", "assaltar", entre outros) e, de alguma forma, isso pode desencadear atitudes por parte dos próprios adolescentes, conforme destacam os excertos 5,6 e 7 , a seguir.

5. Na verdade até eu já mechi com essas porcarias de drogas mas vi que isso não ia me levar a nada. Vários amigos meus já se foram por causa dessa vida maldita, é um caminho quase sem volta, que só você perde, num ganha nada só um fim trágico. (Gabrǐ̌l - 16 anos - Atividade 2)

6. Eu já pasei muita coisa nessa vida, as vezes com droga. Eu agradeço a Deus pela minha família que eu tenho e já ganhei muito conselho do meu irmão que já passou pelas mesma coisa que eu passei. (ĐчÎ̃

7. Bom eu acho isso tudo já normal. (...) Eu já convivi em lugares assim, já fiz coisa do tipo, só que descobri que não tem graça, você acaba com sua vida, você perde sua dignidade. (...) De um lado é legal, você se sente poderoso, o rei do pedaço, de outro você está acabando com sua vida e qualquer hora tu pode morrer com um tiro na cabeça. (Gû̃ovanna - 16 anos - Atividade 2)

Nos excertos (5), (6) e (7), observa-se que os adolescentes se colocam na posição de Sujeito das unidades de informação para mostrar que se trata de uma experiência pessoal e íntima com o perigo que "o lugar onde eles vivem" representa e como esse lugar pode definir o comportamento desses jovens. Destaca-se a ocorrência de circunstâncias de companhia, conforme mostram as expressões seguintes: com essas porcarias de drogas, em (5), com drogas, em (6); em lugares assim, em (7). Tais circunstâncias estão associadas a atitudes, caracterizadas pelos verbos "mexer", "passar" e "conviver". Na fala desses adolescentes, trata-se de uma realidade deles e essa realidade vai definir o que eles são ou o caminho que eles vão seguir. Ou seja, dentro do contexto das ruas: eu vi isso (vi drogas, vi violência, conforme destacam os excertos 3 e 4); ou eu fiz aquilo (mexi com essas porcarias de drogas, como registra o excerto 5). Observe-se, ao longo dos excertos (5), (6) e (7), que os adolescentes avaliam o próprio comportamento (vi que isso não ia me levar a nada; só que descobri que não tem graça, você acaba com sua vida, você perde sua dignidade) ao mesmo tempo em que denunciam uma série de processos que apontam para uma exclusão social.

Nessa perspectiva, a gramática da experiência desses adolescentes mostra que eles estão excluídos de direitos básicos: direito de não ter contato com drogas, por exemplo. A propósito, esse é direito assegurado pela Lei $\mathrm{n}^{\circ}$ 8.069, de 13 de julho de 1990, que dispõe 204 
sobre o Estatuto da Criança e do Adolescente (ECA). O ECA, em seu artigo 19, prevê que "toda a criança ou adolescente tem direito a ser criado e educado no seio da sua família e, excepcionalmente, em família substituta, assegurada a convivência familiar e comunitária, em ambiente livre da presença de pessoas dependentes de substâncias entorpecentes" (negritado meu). Entretanto, o contexto, descrito nos excertos de (1) a (7), deste artigo, mostra que esse direito parece não ter alcançado, pelo menos os adolescentes colaboradores desta pesquisa. Trata-se de um contexto de risco que é representado como algo banal, por isso tá internalizado na gramática da experiência desses jovens - é o que denuncia abertamente a adolescente Gî̀ovanna, de 16 anos, quando avalia: Bom eu acho isso tudo já normal, por que ta acontecendo na nossa sociedade.

Em meio a um processo de socialização que banaliza a acessibilidade às drogas, os adolescentes se submetem a esse contexto sem questionarem a sua condição de excluído de direitos básicos de cidadania, mesmo que apontem para uma consciência crítica a qual lhes permite denunciar a condição de risco em que estão inseridos, como sugerem as unidades de informação extraídas dos excertos (5) e (7), reescritas aqui: é um caminho quase sem volta, que só você perde, num ganha nada só um fim trágico; ou você está acabando com sua vida e qualquer hora tu pode morrer com um tiro na cabeça. Tais unidades de informação, assim como teor dos relatos analisados neste artigo, mostram que esses jovens tem uma historicidade discursiva. O discurso dos adolescentes dá voz a práticas sociais (de socialização) que evidenciam a construção de seus projetos de vida dentro do lugar onde vivem.

E nesse mapeamento da gramática da experiência dos adolescentes, torna-se evidente um nível acentuado de naturalização do contexto descrito, o qual se mostra internalizado em seus discursos. Representar o lugar onde vive como um lugar perigoso se transforma, então, em um dilema para esses jovens, tendo em vista que o uso de drogas pode se tornar um caminho quase sem volta, como sugeriu o excerto (5) - que os colocam em uma condição de risco iminente. Tal condição, mais do que evidenciar um processo de socialização e naturalização da violência urbana, conduz a uma autodestruição que os colocam na contramão da cidadania. 


\section{Considerações finais}

A presente pesquisa se torna significativa se levarmos em conta o grande número de jovens que sentem a necessidade de "falar" sobre todas as mazelas que as "condições de risco" (apontadas aqui) oferecem, o que pode ser feito por meio de textos produzidos em sala de aula em eventos de letramento com textos jurídicos. Nesse sentido, oferecer eventos de letramento pode ser uma boa estratégia para o professor que, ao assumir um papel de educador, perscruta os anseios dos alunos, e, de forma colaborativa, cria mecanismos que possibilitem levar esses estudantes a terem uma visão crítica da realidade, com o propósito de fortalecer a identidade de um grupo massacrado pela violência urbana, pelas drogas e pela ineficácia das leis.

Sabemos que o assunto em pauta, pelo menos no Brasil, é relativamente novo no contexto dos estudos da Gramática Sistêmico Funcional. Sendo assim, nossa análise corre o risco de fazer observações superficiais ou tirar conclusões precipitadas. Sem ter respostas prontas, ou mesmo propostas de caminhos para mitigar essa situação de exclusão social, traduzida pela gramática da experiência de adolescentes de uma escola da rede pública de ensino de Santa Maria, no Distrito Federal, o presente artigo propõe um convite para suscitar questões e estimular futuros debates.

Recebido em: abril de 2015

Aprovado em: maio de 2015

miguelangelo@unb.br

\section{Referências bibliográficas}

BRASIL. Estatuto da Criança e do Adolescente. Secretaria Especial dos Direitos Humanos; Ministério da Educação, Assessoria de Comunicação Social. Brasília: MEC, ACS, 2005.

CHOULIARAKI, Lilie e FAIRCLOUGH, Norman. Discourse in late modernity: rethinking Critical Discourse Analysis. Edinbourg: Edinbourg University, 1999.

CUNHA, Maria Angélica e SOUZA, Maria Medianeira. Transitividade e seus contextos de uso. Rio de Janeiro: Lucerna, 2007.

EGGINS, Suzanne. An introduction to systemic functional linguistics. New York - London: Continuum, 2004.

EGGINS, Suzanne e SLADE, Diana. Analysing casual conversation. London: Cassel, 1997.

FAIRCLOUGH, Norman. Analysing discourse. Textual analysis for social research. London and New York: Routledge, 2003. 
GHIO, Elza e FERNÁNDEZ, Ma. Délia. Manual de linguistica sistêmico funcional: el enfoque de M.A.K. Halliday y R. Hasan: aplicaciones a la lengua española. $1^{a}$ edição - Santa Fé: Universidad Nacional del Litoral, 2005.

HALLIDAY, M. A. K. e MATTHIESSEN, Christian. An introduction to functional grammar. $4^{\mathrm{a}}$ ed. Londres: Arnold, 2014.

MARTIN, James Robert e WHITE, Peter. The language of evalution: Appraisal in English. London: Palgrave Macmillan, 2005.

MOREIRA, Miguel Ângelo. Ruptura familiar e pobreza: a gramática da experiência no discurso de adolescentes. Dissertação inédita (Mestrado em Linguística) - Programa de PósGraduação em Linguística, Universidade de Brasília, Brasília, 2007.

, Miguel Ângelo. A gramática da experiência no discurso de adolescentes: da ruptura familiar parcial às ruas. In: SILVA, Denize Elena G. da; LEAL, Maria Christina D. PACHECO, Marta Carvalho de N. Discurso em questão: representação, gênero, identidade, discriminação. Goiânia: Cânone Editorial, 2009.

Miguel Ângelo. Gêneros textuais, identidade, interpretação e produção textual: interpretando e construindo valores a partir de oficinas de letramento. Projeto desenvolvido numa escola da rede pública de ensino de Santa Maria, no Distrito Federal, Brasília, 2012.

NOVO, Helerina A. De fatos e espetáculos: o imaginário social sobre a violência na Grande Vitória-ES. In: Violência, exclusão social e desenvolvimento humano: estudos em representações sociais. Brasília: Editora Universidade de Brasília, 2006. p. 39-54.

VIAN JR, Orlando; SOUZA, Anderson Alves; ALMEIDA, Fabíola A.S.D.P (org). A linguagem da avaliação em língua portuguesa: estudos sistêmico-funcionais com base no sistema de avaliatividade. São Carlos: Pedro \& João Editores, 2010. 